\title{
Mucinous Cystic Neoplasm of the Pancreas With Extensive Squamous Metaplasia
}

\author{
Abul Ala Syed Rifat Mannan ${ }^{\mathrm{a}}$, June S. Peng ${ }^{\mathrm{b}}$, Gareth Morris-Stiff ${ }^{\mathrm{b}}$, R. Matthew Walsh ${ }^{\mathrm{b}}$, \\ John Hartc ${ }^{\mathrm{c}}$ Xiuli Liu ${ }^{\mathrm{d}}$ e
}

\begin{abstract}
Mucinous cystic neoplasm $(\mathrm{MCN})$ of the pancreas with extensive squamous metaplasia of the lining epithelium is an extremely rare entity. We report such a case in a 25 -year-old woman who underwent distal pancreatectomy for a cystic lesion of the pancreatic tail associated with left upper quadrant pain and acute pancreatitis. Microscopic examination revealed a cystic lesion lined entirely by squamous epithelium with subepithelial ovarian-type stroma, which demonstrated immunoreactivity for CD10, estrogen receptor, and FOXL2. Examination of the entire mass did not reveal any obvious lymphoid tissue, mucinous epithelium or endometrial type glands. We present this case to highlight extensive squamous metaplasia as a rare phenomenon in an otherwise typical MCN of the pancreas.
\end{abstract}

Keywords: Mucinous cystic neoplasm; FOXL2; Ovarian-type stroma; Squamous metaplasia

\section{Introduction}

Mucinous cystic neoplasms (MCNs) are unique cystic pancreatic neoplasms with distinctive clinicopathologic characteristics. They are seen almost exclusively in women $[1,2]$ in the fifth to sixth decades of life [3], and most commonly located in the pancreatic tail [1]. Histologically, MCNs are lined by tall, columnar, mucin-producing cells, with underlying dense ovarian-type stroma, which is considered to be a defining fea-

Manuscript accepted for publication December 09, 2015

aDepartment of Pathology, Mount Sinai St.-Luke's Roosevelt Hospital Center, New York, NY, USA

${ }^{b}$ Department of General Surgery, Digestive Disease Institute, Cleveland Clinic Foundation, Cleveland, OH, USA

'Department of Pathology, University of Chicago, IL, USA

dDepartment of Anatomic Pathology, Cleveland Clinic Foundation, Cleveland, $\mathrm{OH}$, USA

${ }^{e}$ Corresponding Author: Xiuli Liu, Department of Anatomic Pathology, Cleveland Clinic Foundation, 9500 Euclid Avenue/L25, Cleveland, OH 44195, USA.Email: liux3@ccf.org

doi: http://dx.doi.org/10.14740/jmc2388w ture to this entity [4]. Based on the degree of dysplasia of the surface epithelium, the World Health Organization subcategorizes non-invasive $\mathrm{MCNs}$ into MCNs with low, intermediate or high-grade dysplasia [4]. MCNs with extensive squamous metaplasia of the epithelium are extremely rare, with only one previously reported case in the literature [5]. We report a unique case of non-invasive pancreatic MCN with extensive squamous metaplasia and highlight the importance of recognizing this unusual feature.

\section{Case Report}

\section{Clinical presentation}

The patient was a 25 -year-old woman who was diagnosed with an incidental cystic lesion of the pancreatic tail during workup for abdominal pain. Computed tomography (CT) of the abdomen showed a $3.2 \mathrm{~cm}$ cyst of the pancreatic tail but the patient was subsequently lost to follow-up. She presented 2 years later with acute pancreatitis and a repeat $\mathrm{CT}$ demonstrated enlargement of the cyst to $4.3 \mathrm{~cm}$ (Fig. 1a). Magnetic resonance imaging (MRI) demonstrated a non-enhancing, fluid-filled cyst with intracystic debris, without septation or solid component, and without a clear connection to the pancreatic duct (Fig. 1b). Due to symptoms from the cyst and typical appearance for $\mathrm{MCN}$, resection was recommended without further diagnostic testing or fluid sampling. A laparoscopic distal pancreatectomy and splenectomy was performed. The patient's postoperative course was complicated by a grade A pancreatic fistula, which was managed with delayed removal of the surgical drain. The patient did well with no further episodes of pancreatitis and no evidence of recurrence at 42 months of follow-up.

\section{Pathologic findings}

Macroscopic examination of the distal pancreatectomy specimen revealed a $4.1 \times 3.3 \times 3.0 \mathrm{~cm}$, uniloculated, thin-walled cyst, located $1.1 \mathrm{~cm}$ from the distal resection margin, and adjacent to, but not grossly involving the pancreatic duct. The cyst was filled with gray-tan, gelatinous fluid. The average thickness of the cyst wall was $0.3 \mathrm{~cm}$. The inner surface was smooth and devoid of any papillary excrescences. The unin- 

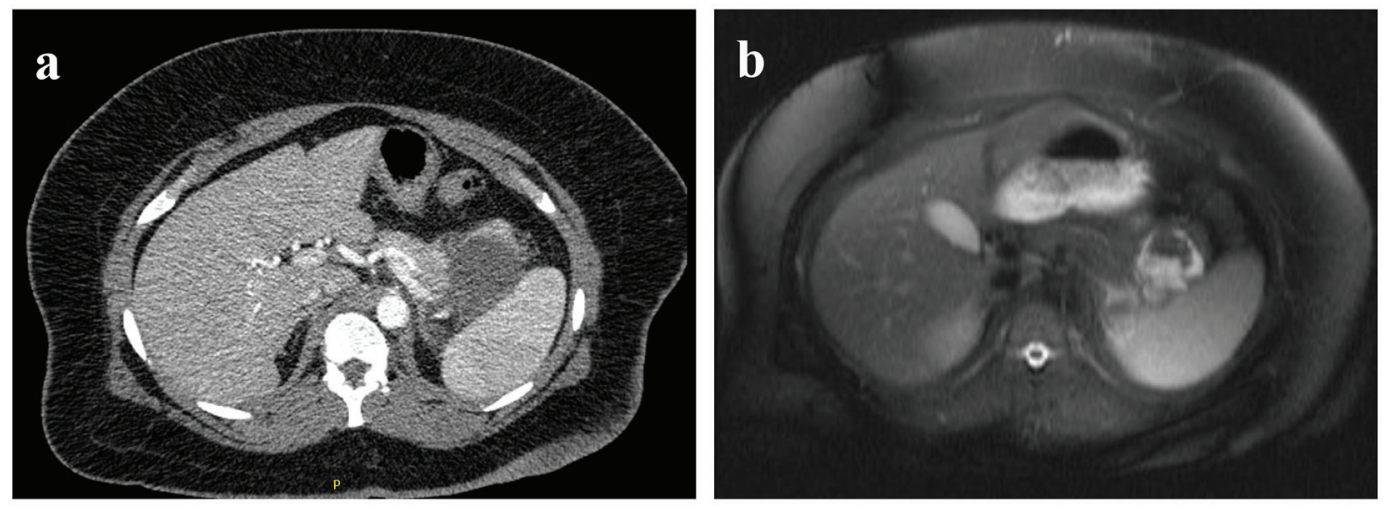

Figure 1. (a) Preoperative CT and (b) MRI of the cyst.

volved pancreatic tissue was grossly unremarkable. The entire cyst was submitted for histology.

Microscopic examination revealed a cystic lesion lined entirely by flattened benign squamous epithelium with focal surface ulceration (Fig. 2a). The subepithelium demonstrated prominent ovarian-type stroma, composed of densely packed spindle-shaped cells with elongated nuclei and sparse cytoplasm (Fig. 2b). The stroma also had areas of dense lymphoplasmacytic inflammation, focal xanthomatous inflammation, and focal ossification. The ovarian-type stroma was immunoreactive for CD10, estrogen receptor (ER) (Fig. 3), and FOXL2 (Fig. 4), but negative for inhibin. Examination of the entire mass did not reveal any discrete lymphoid aggregates, mucinous epithelium, or endometrial type glands. Due to extensive squamous metaplasia, the presence and dysplasia of the glandular epithelium could not be commented on. There was no evidence of malignancy. Adjacent pancreas had evidence of atrophy and fibrosis. A final diagnosis of $\mathrm{MCN}$ of the pancreas with extensive squamous metaplasia was rendered.

\section{Discussion}

MCNs represent approximately $25 \%$ of resected pancreatic cystic neoplasms (PCNs) [1]. They are distinctive PCNs that usually do not communicate with the pancreatic ductal system. Histologically, they are characterized by a tall columnar mucin secreting epithelium, supported by an ovarian-type stroma. The epithelium can undergo different metaplastic changes, such as pseudopyloric, gastric foveolar, and small and large intestinal types $[4,6]$. Extensive squamous metaplasia is very rare. To our knowledge, Li et al [5] reported the only case of extensive squamous metaplasia of an MCN of the pancreas. They described a 39 -year-old woman with a cystic mass in the tail of the pancreas, which was resected and revealed a cyst lined by columnar mucin-producing epithelium with intermediate-grade dysplasia and areas of extensive squamous metaplasia. The subepithelium had characteristic ovarian-type stroma, which was immunoreactive for CD10, ER and progesterone receptor (PR). Their patient had undergone a cystojejunostomy 3 years prior to her distal pancreatectomy. It is debatable whether the squamous metaplasia of the MCN in that case was due to inflammation after cystojejunostomy or a true neoplastic process with squamous cells arising from pluripotent stem cells.

The pathology in our current case was unique, with extensive squamous metaplasia of the epithelium. Despite complete sampling of the cyst and meticulous microscopic examination, we were unable to identify any obvious cyst-lining columnar epithelium. This may be attributed to extensive replacement
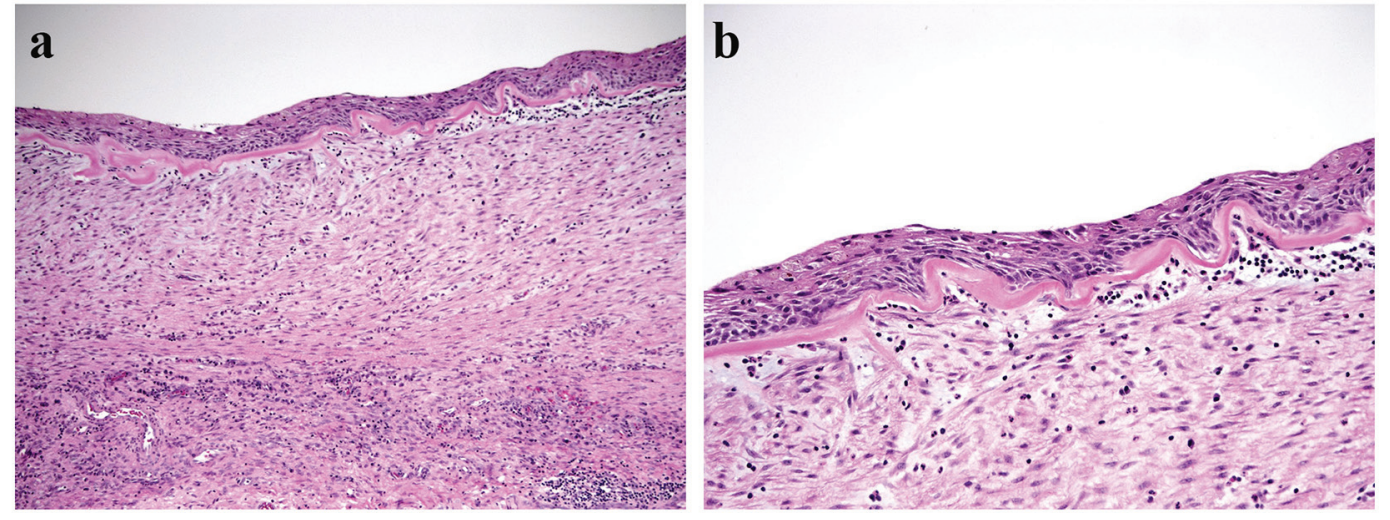

Figure 2. (a) Cyst wall lined by squamous epithelium with a subepithelial ovarian type stroma (hematoxylin \& eosin, $\times 100$ ). (b) Higher magnification of the cyst wall (hematoxylin \& eosin, $\times 200$ ). 


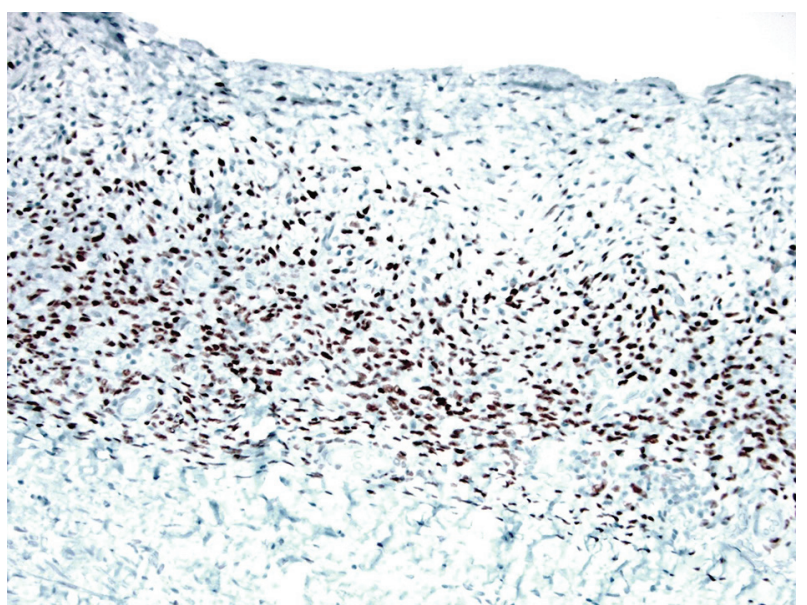

Figure 3. The ovarian-type stroma showing strong and diffuse nuclear positivity for estrogen receptor (immunoperoxidase stain, $\times 200$ ).

of the columnar epithelium by metaplastic squamous epithelium. Other considerations include focal surface ulceration of columnar epithelium. Cystic fluid detection of mucin and CEA may have helped definitively classify this lesion as pancreatic MCN; however, these studies were not performed preoperatively in this patient. The pathogenesis of such extensive squamous metaplasia is unclear. $\mathrm{Li}$ et al [5] suggested that squamous element might be derived from squamous transdifferentiation of the adenomatous element or derived from pluripotent stem cells. In the current case, we observed dense lymphoplasmacytic inflammation of the underlying stroma, with focal xanthomatous change and focal ossification. It is likely that the extensive squamous metaplasia in our case may be also related to long-standing inflammation.

$\mathrm{MCN}$ belongs to a distinctive group of non-ovarian cystic tumors which also includes hepatobiliary cystadenoma (HBC) and mixed epithelial and stromal tumor of the kidney (MEST), which are characterized by the presence of ovarian-type stroma [7-9]. The stroma in these neoplasms has been reported to variably express ER and PR $[8,10]$. Most recently, Westerhoff et al [11] reported expression of FOXL2 (a transcription factor expressed in normal ovaries and ovarian sex cord stromal tumors) in the ovarian-type stroma of MCN, HBC and MESTs. In the current case, the ovarian-type stroma which lined the entire cyst wall demonstrated strong and diffuse nuclear positivity in FOXL2. This finding further leads credence to the assertion that the present case was indeed MCN with extensive squamous metaplasia of the epithelium.

It is imperative to differentiate MCN from other PCNs and pseudocysts. Pathologic differentiation of MCNs from pseudocysts may become a morphologic problem, since some MCNs can undergo extensive degenerative change with denudation of the epithelium. Extensive sampling is required to look for mucinous epithelium and/or characteristic ovarian-type stroma [6]. Mucinous non-neoplastic cysts can pose a diagnostic dilemma as well, although clinically, these have equal prevalence in males and females, commonly involve the pancreatic head, often communicate with the pancreatic duct, and pathologically, are without ovarian-type stroma $[4,12]$. Differentiat-

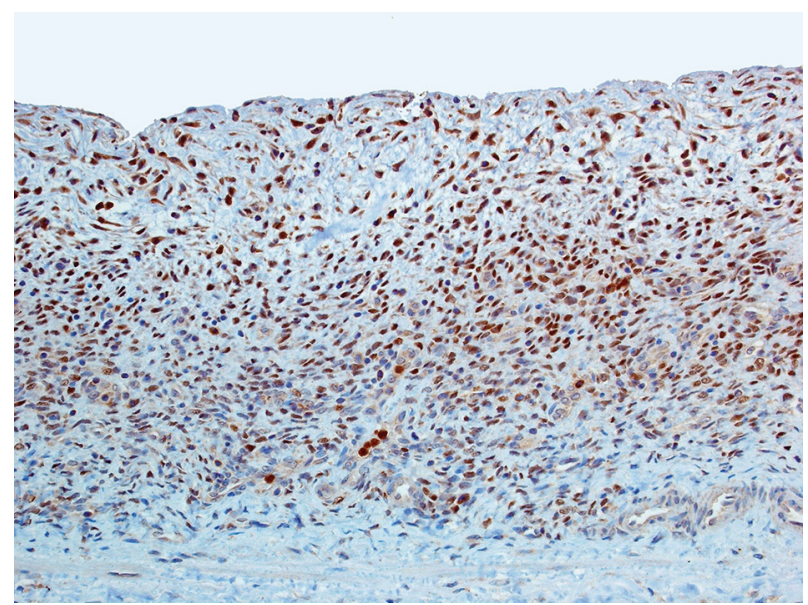

Figure 4. FOXL2 highlights the ovarian-type stroma with strong nuclear reactivity (immunoperoxidase stain, $\times 200$ ).

ing MCN from a branch-duct intraductal papillary mucinous neoplasm (IPMN) can be made by lack of communication with the pancreatic duct and the presence of ovarian-type stroma [4]. Lymphoepithelial cyst (LEC) also enters into differential diagnosis in the current case, as LEC can present as a cystic mass in the tail, lined by squamous epithelium. However, LEC is often characterized by the presence of subepithelial lymphoid aggregates, often with prominent follicles and lack of ovarian-type stroma seen in MCNs [13].

Surgical resection is curative for almost all patients with a non-invasive MCN, with 5-year survival reported to be 94.7$100 \%$ in patients with non-invasive MCNs [14, 15]. Since most tumors are located in the body or tail of the pancreas, laparoscopic or open distal pancreatectomy is often the surgery of choice.

In conclusion, we present a rare case of $\mathrm{MCN}$ of the pancreas in a 25 -year-old woman, with extensive squamous metaplasia of the epithelium. An awareness of this occurrence is important for correct diagnosis. Reporting additional such cases in the future may shed light on the origin of squamous epithelium in pancreatic MCN.

\section{Financial Support}

None.

\section{Conflicts of Interest}

None.

\section{References}

1. Farrell JJ, Fernandez-del Castillo C. Pancreatic cystic neoplasms: management and unanswered questions. Gastroenterology. 2013;144(6):1303-1315.

2. Robinson SM, Scott J, Oppong KW, White SA. What to 
do for the incidental pancreatic cystic lesion? Surg Oncol. 2014;23(3):117-125.

3. Yoon WJ, Brugge WR. Pancreatic cystic neoplasms: diagnosis and management. Gastroenterol Clin North Am. 2012;41(1):103-118.

4. Zamboni G, Fukushima N, Hruban RH, Kloppel G. Mucinous cystic neoplasm of the pancreas. In: Bosman FT, Carneiro F, Hruban RH, Theise ND, eds. World Health Organization Classification of Tumors of the Digestive System, 4th ed. IARC Press: Lyon; 2010.

5. Li P, Wang Y, Zhang Q, Liu Y, Lv Y, Wang Z. A noninvasive mucinous cystic neoplasm with intermediate-grade dysplasia of the pancreas and extensive squamous metaplasia: a case report with clinicopathological correlation. Diagn Pathol. 2012;7:89.

6. Hruban RH, Pitman MB, and Klimstra DS, eds. Tumors of the Pancreas. Armed Force Institute of Pathology: Washington, DC; 2007.

7. Adsay NV. Cystic neoplasia of the pancreas: pathology and biology. J Gastrointest Surg. 2008;12(3):401-404.

8. Adsay NV, Eble JN, Srigley JR, Jones EC, Grignon DJ. Mixed epithelial and stromal tumor of the kidney. Am J Surg Pathol. 2000;24(7):958-970.

9. Devaney K, Goodman ZD, Ishak KG. Hepatobiliary cystadenoma and cystadenocarcinoma. A light microscopic and immunohistochemical study of 70 patients. Am J
Surg Pathol. 1994;18(11):1078-1091.

10. Lam MM, Swanson PE, Upton MP, Yeh MM. Ovariantype stroma in hepatobiliary cystadenomas and pancreatic mucinous cystic neoplasms: an immunohistochemical study. Am J Clin Pathol. 2008;129(2):211-218.

11. Westerhoff M, Tretiakova M, Hart J, Gwin K, Liu X, Zhou M, Yeh MM, et al. The expression of FOXL2 in pancreatic, hepatobiliary, and renal tumors with ovariantype stroma. Hum Pathol. 2014;45(5):1010-1014.

12. Kosmahl M, Egawa N, Schroder S, Carneiro F, Luttges J, Kloppel G. Mucinous nonneoplastic cyst of the pancreas: a novel nonneoplastic cystic change? Mod Pathol. 2002;15(2):154-158.

13. Adsay NV, Hasteh F, Cheng JD, Bejarano PA, Lauwers GY, Batts KP, Kloppel G, et al. Lymphoepithelial cysts of the pancreas: a report of 12 cases and a review of the literature. Mod Pathol. 2002;15(5):492-501.

14. Crippa S, Salvia R, Warshaw AL, Dominguez I, Bassi C, Falconi M, Thayer SP, et al. Mucinous cystic neoplasm of the pancreas is not an aggressive entity: lessons from 163 resected patients. Ann Surg. 2008;247(4):571-579.

15. Yamao K, Yanagisawa A, Takahashi K, Kimura W, Doi R, Fukushima N, Ohike N, et al. Clinicopathological features and prognosis of mucinous cystic neoplasm with ovarian-type stroma: a multi-institutional study of the Japan pancreas society. Pancreas. 2011;40(1):67-71. 